\title{
Análise de leite de búfala fermentado por Lactobacillus casei e \\ suplementado com Bifidobacterium longum
}

\section{Assessment of fermented buffalo milk for Lactobacillus casei and supply with Bifidobacterium longum}

Cláudia Puerari Faria ${ }^{1 *}$; Honório Domingos Benedet ${ }^{2}$; Jean-Louis Le Guerroue ${ }^{3}$

\section{Resumo}

Elaborou-se leite de búfala fermentado por Lactobacillus casei utilizando leite desnatado, adicionado de $12,00 \%$ de açúcar e fermentado por 24 horas. Após fermentação o produto foi suplementado com Bifidobacterium longum e estocado durante 30 dias a 5 e $10^{\circ} \mathrm{C}$, sendo então avaliados os parâmetros de acidez, $\mathrm{pH}$ e viabilidade de L.casei e de B. longum. Realizou-se a análise de composição nutricional, cálculo do valor calórico e análise sensorial do produto saborizado. O leite fermentado suplementado com B. longum, apresentou acidez inicial de $0,69 \%$ e $\mathrm{pH}$ de 4,86. A viabilidade de $L$. casei inicial foi 11,00 $\log \mathrm{UFC} / \mathrm{mL}$ e de $B$. longum 10,46 log UFC/mL. Após 30 dias de estocagem refrigerada, a acidez e o pH estavam adequados e a viabilidade de $L$. casei e de $B$. longum ficou acima de 9,00 log UFC/mL. A análise da composição nutricional resultou nos valores (\%): proteína 3,63, carboidrato 21,86 , gordura 0,10 , resíduo mineral fixo 0,56, umidade 73,85 e matéria seca 26,15, com valor calórico de $103 \mathrm{Kcal} / 100$ g. Não houve diferença significativa na preferência e na aceitação das amostras de diferentes sabores, sendo que o produto apresentou boa aceitação pela escala hedônica.

Palavras-chave: leite fermentado, leite de búfala, probióticos, composição nutricional, Lactobacillus casei, Bifidobacterium longum.

\begin{abstract}
It was elaborated fermented buffalo milk for $L$. casei utilizing skimmed milk added with $12,00 \%$ sugar and fermented by 24 hours. After fermentation, the product was supply with $B$. longum and storage during 30 days at 5 and $10^{\circ} \mathrm{C}$, being evaluated the acidity, $\mathrm{pH}$ and viability of $L$. case $i$ and $B$. longum parameters. Were does the nutritional composition, calculate the caloric value and sensorial analysis of the flavored product. The fermented milk presented initial acidity $0.69 \%$ and $\mathrm{pH} 4.86$. The $L$. casei initial viability was $11,00 \log \mathrm{CFU} / \mathrm{mL}$ and B. longum $10,46 \log \mathrm{CFU} / \mathrm{mL}$. After storage of 30 days, the acidity and $\mathrm{pH}$ were adequate and the $L$. case $i$ and $B$. longum viability was above $9.00 \log C F U / m L$. The composition analysis resulted (\%) protein 3.63 , carbohydrate 21.86 , fat 0.10 , ashes 0.56 , wet 73.85 and dry substance 26.15 , with caloric value $103 \mathrm{Kcal} / 100 \mathrm{~g}$. There wasn't significant difference to preference and acceptance between flavored samples, and have good acceptation by hedonic scale.

Key words: fermented milk, buffalo milk, probiotics, nutritional composition, Lactobacillus casei, Bifidobacterium longum.
\end{abstract}

\footnotetext{
1 Nutricionista, Mestre em Ciência dos Alimentos, Professora Assistente I do Departamento de Alimentos e Nutrição da Faculdade de Nutrição da Universidade Federal de Mato Grosso. - Rua Batista das Neves, Quadra G, Casa 06, Bairro Jardim das Flores CEP: 78.130-700, Várzea Grande - MT, Email: claudiapfaria@ hotmail.com

2 Departamento de Ciência e Tecnologia de Alimentos, Centro de Ciências Agrárias da Universidade Federal de Santa Catarina. Rodovia Admar Gonzaga, 1346, Bairro Itacorubi - CEP: 88.034.001 - Florianópolis - SC, Email: benedet@cca.ufsc.br

3 Universidade Católica de Brasília. Pró-Reitoria de Pós-Graduação e Pesquisa, Universidade Católica de Brasília. SGAN 916, Mod. B, W5 Norte, Asa Norte - CEP: 70790-160. Brasília - DF, Email: guerroue @ pos.ucb.br.
}

* Autor para correspondência 


\section{Introdução}

O leite de búfala é um alimento com elevado teor de nutrientes, sendo uma fonte de proteínas de alto valor biológico, ou seja, que possuem os aminoácidos essenciais em proporções adequadas para a utilização pelo organismo (HUHN et al., 1991; KRAUSE, 1998).

Quando submetido à fermentação, ocorrem modificações nos nutrientes, com o aumento da digestibilidade e da absorção de proteínas, lipídeos e carboidratos. As proteínas sofrem hidrólise parcial e originam polipeptídeos, peptídeos e aminoácidos, formando um coágulo finamente dividido. A absorção de cálcio e de ferro é aumentada. O cálcio passa da forma de caseinato de cálcio para lactato de cálcio e a acidez aumentada auxilia sua absorção (FERREIRA, 1997; GOMES; MALCATA, 1999).

A fermentação caracteriza-se pela utilização parcial dos nutrientes por microrganismos ácidoláticos, que utilizam principalmente a lactose, dando origem ao ácido lático e a outros ácidos orgânicos, como o acético e o propiônico. Estes agem aumentando a acidez até alcançar o ponto isoelétrico da caseína. A acidificação do meio aumenta a solubilidade de minerais como o cálcio orgânico e o fósforo, contidos na micela, tornando-os gradualmente solúveis na fase aquosa. A micela desintegra e a caseína precipita, com posterior agregação como resultado de interações hidrofóbicas entrópicas, que modificam a fluidez (WALSTRA, 1990; FERREIRA, 2001).

Dentre os diferentes tipos de leites fermentados que podem ser obtidos, os produtos elaborados com bactérias probióticas tem despertado grande interesse. São microrganismos vivos que, ingeridos em determinadas quantidades, exercem efeitos benéficos à saúde do hospedeiro, além dos relacionados aos efeitos nutricionais em geral (TRABULSI, 2000).

Os efeitos designados incluem alívio dos sintomas da intolerância à lactose, modulação do sistema imune e da microbiota intestinal (tratamento e prevenção de diarréia) e possível efeito hipocolesterolêmico e ação anticarcinogênica (GOMES; MALCATA, 1999).

Em leites fermentados probióticos geralmente são empregados organismos de espécies isoladas do intestino humano, como Bifidobacterium e Lactobacillus. As bifidobactérias sintetizam vitaminas do complexo B, elevando seu teor no produto fermentado, e o teor de lactose é diminuído em aproximadamente 20 a $25 \%$ devido à sua utilização pelos microrganismos. Bactérias como bifidobactérias e Lactobacillus casei produzem ácido lático L (+), que é de mais fácil digestão para crianças de até um ano de idade, enquanto outros microrganismos produzem a forma D (-) ou DL (+/-) (HOLT et al., 1994; TAMINE, MARSHALL; ROBINSON, 1995; FERREIRA, 1997).

Os diferentes leites fermentados apresentam fases de produção similares, como padronização do conteúdo de gordura, aumento dos sólidos não gordurosos do leite, homogeneização, desaeração e tratamento térmico. Quando se utilizam culturas probióticas torna-se necessário determinar ainda o tipo de cultura starter mais adequada, a temperatura, o tempo de incubação e a taxa de inoculação (TAMINE, MARSHALL; ROBINSON, 1995).

O leite bubalino, por apresentar composição diferente do bovino, com maior conteúdo de sólidos totais e de desengordurados, não requer o aumento de sólidos não gordurosos para a elaboração de iogurte e de outros leites fermentados, obtendo-se viscosidade, textura e aparência adequadas sem a necessidade desta adição (HUHN et al., 1984; BENEVIDES, 1998; HUHN et al., 1991).

O leite fermentado normalmente é ácido, com $\mathrm{pH}$ entre 3,5-4,5, que deve ser alcançado em, no máximo, 24 horas. A porcentagem de ácido lático deve ser, no mínimo, de 0,60\% para garantir a segurança microbiológica do produto. $\mathrm{O}$ ácido lático na concentração de 0,5 a 1,5\% não é inibitório para a cultura microbiana. Entretanto, os íons $\mathrm{H}^{+}$causam um decréscimo na viabilidade das células a valores 
de pH ácidos (LEE; SALMINEN, 1995; BRASIL, 2000).

A produção de leites fermentados com bactérias probióticas é um desafio, pois sua multiplicação é lenta, levando a fermentações longas. Microrganismos como as bifidobactérias produzem ácido acético além do lático (proporção 3:2), criando alterações sensoriais. Para minimizar estas dificuldades de produção é necessário selecionar a estirpe, fazer um tratamento térmico rigoroso e controlar a acidez final do produto. Bifidobacterium longum geralmente é utilizada em leites fermentados probióticos por apresentar melhor tolerância ao oxigênio e por ser a bactéria que mais perdura ao longo da vida dos hospedeiros humanos, podendo ser adicionada após a fermentação para evitar as restrições sensoriais causadas pela produção de ácido acético (GOMES; MALCATA, 1999).

O produto final deve ter vida-de-prateleira média satisfatória (variando de 1 a 30 dias) e propriedades sensoriais agradáveis (cor, aroma, sabor e textura), com os microrganismos permanecendo viáveis e em número suficientemente elevado ( $\left.>10^{6} \mathrm{UFC} / \mathrm{mL}\right)$. Segundo Gomes e Malcata (1999) a dose diária mínima recomendada, usualmente considerada de $10^{8}$ a $10^{9}$ células viáveis, é obtida pelo consumo regular de $100 \mathrm{~g}$ de produto com $10^{6}-10^{7}$ células viáveis $/ \mathrm{mL}$.

Este trabalho foi realizado com o objetivo de avaliar a variação da acidez, do $\mathrm{pH}$ e da viabilidade de $L$. casei e de B. longum durante a estocagem do leite de búfala fermentado, analisar sua composição nutricional e verificar a preferência e aceitação do produto por meio da análise sensorial.

\section{Material e Métodos}

Leite de búfala pasteurizado, desnatado e refrigerado foi obtido de um laticínio localizado na cidade satélite de Ceilândia, DF, entre os meses de junho e outubro de 2004. Para a fermentação foi utilizada cultura comercial liofilizada de inoculação direta (Direct Vat Set, DVS) de Lactobacillus casei subsp. casei $\left(\right.$ Texel $^{\circledR}$ Dried LBC 81) e para a suplementação a cultura liofilizada de Bifidobacterium longum (BL-04, American Type Culture Collection, ATCC n ${ }^{\circ}$. 5219) marca Rhodia ${ }^{\circledR}$.

A cultura de Lactobacillus casei foi diluída de forma asséptica, na concentração recomendada pelo fabricante, em leite em pó desnatado, previamente reconstituído a 12,00\% e esterilizado (LDR 12,00\%), sendo utilizado como inóculo para a fermentação.

O concentrado de Bifidobacterium longum foi obtido após a inoculação asséptica de $1 \mathrm{~g}$ da cultura em $100 \mathrm{~mL}$ de LDR 12,00\%, com incubação a $37^{\circ} \mathrm{C}$ até atingir $0,85 \%$ de acidez em ácido lático, quando foi resfriado. Alíquotas de $10 \mathrm{~mL}$ foram centrifugadas a $3.000 \mathrm{rpm} / 15 \mathrm{~min}$. O sobrenadante foi descartado e o concentrado de células ressuspendido em água estéril, procedendo-se nova centrifugação a 3.000 $\mathrm{rpm} / 15 \mathrm{~min}$. O sobrenadante foi novamente descartado e o concentrado de células foi ressuspendido em $10 \mathrm{~mL}$ de água estéril, sendo este inóculo utilizado para suplementar o leite de búfala fermentado por L. casei (adaptado de CORDEIRO, 1999).

Para elaborar o leite de búfala fermentado por $L$. casei foram utilizados 15 litros de leite de búfala que, após o desnate até $0,10 \%$ de gordura, foi adicionado de $12,00 \%$ de açúcar $(\mathrm{p} / \mathrm{v})$, tratado termicamente a $85^{\circ} \mathrm{C} / 15$ min e resfriado em banho de gelo até alcançar $37^{\circ} \mathrm{C}$. Adicionou-se $2,50 \%$ do inóculo de $L$. casei subsp. casei e incubou-se em estufa a $37^{\circ} \mathrm{C}$ por 24 horas.

Ao término do período de fermentação, o produto foi resfriado e armazenado a $5^{\circ} \mathrm{C}$ por 24 horas para obter uma coalhada mais líquida após sua quebra, sendo então retirados 9 litros para a análise sensorial e de microrganismos de alteração. O restante foi suplementado com $1,00 \%$ de B. longum e estocado a 5 e $10^{\circ} \mathrm{C}$ por 30 dias para as análises de acidez, $\mathrm{pH}$, composição nutricional, cálculo do valor calórico e análise da viabilidade das bactérias probióticas.

A análise de microrganismos de alteração foi realizada no leite de búfala tratado termicamente para 
verificar a presença de aeróbios mesófilos (contagem padrão em placas). No leite fermentado foram realizadas as análises de coliformes a $35^{\circ} \mathrm{C}$ e a $45^{\circ} \mathrm{C}$ utilizando-se o método do Número Mais Provável e análise de bolores e leveduras por meio de plaqueamento em superfície (VANDERZANT; SPLITTSTOESSER, 2002).

Foram realizadas análises de acidez (\% de ácido lático) e pH em duplicata nos tempos 24 horas, 7, 14, 21 e 30 dias, utilizando-se a metodologia descrita pela Association of Official Analytical Chemist - AOAC (1999).

Para a análise da viabilidade das bactérias probióticas utilizou-se o meio MRS (De Man, Rogosa e Sharpe) modificado com a adição de $0,15 \%(\mathrm{p} / \mathrm{v})$ de bile (MRS-bile) para a contagem de L. casei subsp. casei, com incubação a $37^{\circ} \mathrm{C}$ por 72 horas sob aerobiose e o meio MRS modificado com a adição de $0,20 \%(\mathrm{p} / \mathrm{v})$ de cloreto de lítio e $0,30 \%(\mathrm{p} / \mathrm{v})$ de propionato de sódio (MRS-LP) para a contagem de B. longum, com incubação a $37^{\circ} \mathrm{C}$ por 72 horas, sob anaerobiose. Após a incubação, realizou-se a contagem das colônias típicas de $L$. casei e de $B$. longum (VINDEROLA; REINHEIMER, 2000).

A composição nutricional do leite de búfala desnatado e do leite fermentado foi obtida em triplicata, tendo sido realizadas as análises de umidade, matéria seca, resíduo mineral fixo (RMF), proteína (determinação de $\mathrm{N}$ total) e gordura segundo a metodologia da AOAC (1999). O percentual de carboidratos foi obtido pela diferença dos demais constituintes.

O cálculo do valor calórico do leite de búfala e do leite fermentado, em quilocalorias (Kcal), foi realizado multiplicando-se a porcentagem obtida de proteína e de carboidrato por 4 e a porcentagem obtida de gordura por 9. Estes são valores estimados aproximados da energia disponível nos respectivos nutrientes para a utilização pelo organismo (AVESANI, SANTOS; CUPPARI, 2002).

Para a análise sensorial, o produto foi dividido em três porções e preparado nos sabores laranja, maçãverde e pêssego. Avaliou-se a preferência utilizando o teste de ordenação e a aceitação do produto empregando o de escala hedônica de nove pontos. O painel foi composto por 50 julgadores não treinados e as amostras foram aleatorizadas em blocos inteiramente casualizados. A análise de microrganismos de alteração (coliformes a $35^{\circ} \mathrm{C}$ e a $45^{\circ} \mathrm{C}$, bolores e leveduras) foi efetuada antes de realizar a análise sensorial, para verificar a qualidade microbiológica do produto.

\section{Resultados e Discussão}

O leite de búfala desnatado tratado termicamente utilizado para a elaboração do leite fermentado apresentou valor de $\mathrm{pH}$ de 6,69 $\pm 0,04$, acidez $0,18 \pm$ $0,02 \%$ de ácido lático e contagem de aeróbios mesófilos de 1,0 x $10^{1} \mathrm{UFC} / \mathrm{mL}$ (est.), indicando boa qualidade microbiológica da matéria-prima utilizada e efetividade do tratamento térmico. O leite de búfala fermentado atendeu aos padrões microbiológicos recomendados pela legislação (bolores e leveduras $<10 \mathrm{UFC} / \mathrm{mL}$, coliformes a $45^{\circ} \mathrm{C}<0,3 \mathrm{NMP} / \mathrm{mL}$ ) (BRASIL, 2000).

O leite de búfala fermentado por L. casei e suplementado com $B$. longum apresentou acidez inicial média de 0,69 $\pm 0,01 \%$ de ácido lático e a final (30 dias) chegou a $1,30 \pm 0,02 \%$ no produto estocado a $5^{\circ} \mathrm{C}$ e a $1,22 \pm 0,06 \%$ no estocado a $10^{\circ} \mathrm{C}$. $\mathrm{O}$ valor de $\mathrm{pH}$ no tempo 1 dia foi de 4,86 $\pm 0,00$ e no 30 dias foi $4,64 \pm 0,01$ para o produto estocado a $5^{\circ} \mathrm{C}$ e de $4,38 \pm 0,00$ para o mantido a $10^{\circ} \mathrm{C}$ (Tabela 1 ). 
Tabela 1 - Valores médios \pm desvio-padrão de acidez, pH e viabilidade de $L$. casei e de B. longum em leite de búfala fermentado por 24 horas, com 12,00\% de açúcar e estocado sob refrigeração por 30 dias.

\begin{tabular}{cccccc}
\hline $\begin{array}{c}\text { Tempo de } \\
\text { estocagem } \\
\text { (dias) }\end{array}$ & $\begin{array}{c}\text { Temperatura de } \\
\text { estocagem }\left({ }^{\circ} \mathrm{C}\right)\end{array}$ & Acidez $*(\%)$ & $\mathrm{pH}^{*}$ & $\begin{array}{c}\text { Viabilidade de } \\
\text { L. casei }(\log \\
\text { UFC/mL)* }\end{array}$ & $\begin{array}{c}\text { Viabilidade de } \\
\text { B. longum }(\log \text { UFC } / \mathrm{mL})^{*}\end{array}$ \\
\hline 1 & 5 & $0,69 \pm 0,01$ & $4,86 \pm 0,00$ & 11,00 & 10,46 \\
7 & 10 & $0,69 \pm 0,01$ & $4,86 \pm 0,00$ & 11,00 & 10,46 \\
& 5 & $1,02 \pm 0,04$ & $4,65 \pm 0,01$ & - & - \\
14 & 10 & $1,16 \pm 0,01$ & $4,52 \pm 0,01$ & - & 10,23 \\
& 5 & $1,03 \pm 0,16$ & $4,55 \pm 0,01$ & 10,45 & 10,18 \\
21 & 10 & $1,26 \pm 0,00$ & $4,34 \pm 0,00$ & 10,11 & - \\
& 5 & $1,21 \pm 0,00$ & $4,73 \pm 0,02$ & - & - \\
30 & 10 & $1,30 \pm 0,02$ & $4,48 \pm 0,00$ & - & 9,92 \\
\hline
\end{tabular}

* média de duas mensurações.

Os valores de acidez e $\mathrm{pH}$ permitem verificar que o tempo de fermentação foi suficiente para alcançar a acidez inicial desejável para o leite fermentado de, no mínimo, 0,60\% de ácido lático e o pH entre 4,50 e 5,00, necessário para garantir a inibição do desenvolvimento de microrganismos patogênicos e deteriorantes que porventura sobrevivam ao tratamento térmico e que poderiam alterar o produto durante sua vida-de-prateleira (BRASIL, 2000).

Ao mesmo tempo, a acidez final ficou abaixo de $2,00 \%$ e o valor de $\mathrm{pH}$ acima de 4,00, valores satisfatórios, que não apresentam efeito prejudicial sobre a viabilidade das bactérias probióticas (LEE; SALMINEN, 1995).

Em relação à viabilidade de $L$. casei e de $B$. longum, o número inicial médio de $\mathrm{UFC} / \mathrm{mL}(\log )$ para L. casei foi 11,00 e o final variou entre 10,08 para o produto estocado a $5^{\circ} \mathrm{C}$ e 9,63 para a estocagem a $10^{\circ} \mathrm{C}$. A viabilidade média de $B$. longum foi $10,46 \log \mathrm{UFC} / \mathrm{mL}$ no tempo inicial, variando entre 9,92 e 9,60 log UFC/mL no tempo final para o produto estocado a 5 e $10^{\circ} \mathrm{C}$, respectivamente.

Segundo Adams e Moss (2000), a combinação de baixo $\mathrm{pH}$ e o acréscimo de acidez poderiam resultar em aumento de ácido não dissociado, o qual é mais danoso aos microrganismos e é claramente um fator no rápido decréscimo da população de bifidobactérias durante a vida-de-prateleira do produto.
Observa-se que, apesar da redução no número de células viáveis no produto estocado, a perda de viabilidade não foi significativa, pois tanto as contagens de L. casei quanto as de B. longum se mantiveram acima do mínimo recomendado para produtos contendo probióticos, que é de 6,00 log UFC/mL. Portanto, a variação da acidez e do $\mathrm{pH}$ observada durante a estocagem do produto não foi prejudicial à viabilidade das bactérias probióticas.

A manutenção da viabilidade de $L$. casei e de $B$. longum à temperatura de 5 e $10^{\circ} \mathrm{C}$ também é um resultado importante, pois sabe-se que existem sérios problemas na continuidade da cadeia de frio durante a distribuição e venda de laticínios e no atendimento dos critérios de temperatura adequados para o armazenamento destes produtos. A temperatura de balcões refrigerados geralmente fica próxima de $10^{\circ} \mathrm{C}$.

O produto obtido apresentou, sob inspeção visual, coalhada firme, com pouca sinérese, mesmo após a quebra da coalhada e estocagem refrigerada, sendo estas características desejáveis para o leite fermentado. Como o leite de búfala possui elevado conteúdo de proteínas, principalmente de caseínas, valor que é superior ao encontrado no bovino, obtevese um produto com menor quantidade de água livre, devido à capacidade de retenção pelas proteínas, dispensando desta forma a adição de qualquer tipo de espessante ao produto (HUHN et al., 1991). 
Os resultados da análise da composição nutricional do leite de búfala fermentado foram, em \%, proteína 3,63 , carboidrato 21,86 , gordura 0,10 , RMF 0,56 , umidade 73,85 e matéria seca 26,15 , com valor calórico de $103 \mathrm{Kcal} / 100 \mathrm{~g}$.

Embora não haja uma legislação específica com padrões para produtos derivados do leite de búfala, os teores de proteína e de gordura encontram-se dentro dos recomendado para leites fermentados desnatados (gordura máxima de 0,5 g / $100 \mathrm{~g}$ e proteína mínima de 2,9 g / 100 g) (BRASIL, 2000).

A composição nutricional verificada é semelhante à obtida por Cordeiro (1999), que utilizou leite de vaca para produzir leite fermentado por L. casei. Por ter sido utilizado neste trabalho o leite de búfala desnatado, obteve-se valores superiores, em \%, de proteína $(3,63$ contra 2,12$)$, de carboidrato $(21,86$ contra 12,70$)$ e de $\operatorname{RMF}(0,56$ contra 0,45$)$ do que os obtidos para o produto elaborado com leite de vaca e inferiores de gordura $(0,10$ contra 0,60$)$ e umidade $(84,16$ contra 88,65$)$.

Outro trabalho realizado por Añiguez Rojas, Cardoso e González (2001) utilizando leite de búfala integral para elaborar leite fermentado por Bifidobacterium bifidum apresentou composição centesimal, em \%, de 3,92 de proteína, 5,82 de gordura, 12,20 de carboidrato, 0,58 de RMF e 22,52 de sólidos totais, com valor calórico de $116 \mathrm{Kcal} /$ $100 \mathrm{~g}$.

Portanto, o leite de búfala fermentado apresenta maior valor nutricional que o de vaca fermentado devido à maior concentração de proteína, lactose, vitaminas e minerais. Além disso, com a fermentação, há um acréscimo da digestibilidade e da absorção dos nutrientes, favorecendo a utilização pelo organismo.

Os resultados da análise sensorial para o teste de ordenação são apresentados na Tabela 2. Ao aplicar o teste de Friedman verifica-se que a diferença entre as médias não foi significativa ao nível de 5\% (calculado 4,12; tabelado 5,99).
Tabela 2 - Soma das ordens do leite fermentado saborizado segundo o teste de ordenação.

\begin{tabular}{lc}
\hline \multicolumn{1}{c}{$\begin{array}{c}\text { Leite de búfala } \\
\text { fermentado sabor }\end{array}$} & Soma das ordenações* \\
\hline laranja & $111^{\mathrm{a}}$ \\
maçã-verde & $98^{\mathrm{a}}$ \\
pêssego & $91^{\mathrm{a}}$ \\
\hline
\end{tabular}

* resultados sobrescritos por letras iguais não diferem entre si, pelo teste de Friedman ( $\mathrm{p}=0,05)$.

As notas obtidas no teste de escala hedônica são apresentadas na Tabela 3. A média variou de 6,68 a 6,98 , que correspondem às classificações "gostei ligeiramente" e "gostei moderadamente", o que sugere que o produto apresentou boa aceitação sob o ponto de vista sensorial. Não houve diferença significativa na aceitação dos diferentes sabores do leite fermentado ao nível de $5 \%$.

Tabela 3 - Resultados das notas atribuídas no teste de escala hedônica.

\begin{tabular}{cccc}
\hline Sabor & Média \pm DP* & Máximo & Mínimo \\
\hline Laranja & $6,68 \pm 1,98^{\text {a }}$ & 9,0 & 2,0 \\
Maçã-verde & $6,98 \pm 1,49^{\text {a }}$ & 9,0 & 3,0 \\
Pêssego & $6,88 \pm 1,75^{\text {a }}$ & 9,0 & 2,0 \\
\hline
\end{tabular}

* resultados sobrescritos por letras iguais não diferem entre si, pela análise de variância $(\mathrm{p}=0,05)$.

\section{Conclusões}

O leite de búfala fermentado por L casei e suplementado com B. longum alcançou valores de acidez e $\mathrm{pH}$ iniciais e finais desejáveis, sendo que a viabilidade de $L$. casei e de B. longum foi mantida acima de $10^{6} \mathrm{UFC} / \mathrm{mL}$ ao longo de 30 dias, podendo considerar o produto como leite fermentado probiótico.

Apresentou qualidade microbiológica adequada, dentro dos padrões legais para leite fermentado e a análise da composição nutricional permite sua classificação como leite fermentado desnatado de acordo com os padrões da legislação vigentes para leite fermentado bovino. 
Pela análise sensorial apresentou boa aceitação no teste de escala hedônica e não houve diferença significativa na preferência e na aceitação dos diferentes sabores.

\section{Referências}

ADAMS, M. R.; MOSS, M. O. Food microbiology. Cambridge: The Royal Society of Chemistry, 2000. 494p.

AÑIGUEZ ROJAS, C.; CARDOSO, F.; GONZÁLEZ, J. Desarrollo de una leche fermentada a partir de leche de búfala con adición de Bifidobacterium bifidum. Alimentaria: Revista de Tecnología e Higiene de los Alimentos, Madri, v.38, n.327, p.97-100, 2001.

ASSOCIATION OF OFFICIAL ANALYTICAL CHEMIST. Official methods of analysis of AOAC international. 16.ed. USA: AOAC International, 1999.

AVESANI, C. M.; SANTOS, N. S. J.; CUPPARI, L. Necessidades e recomendações de energia. In: CUPPARI, L. Guia de nutrição: nutrição clínica no adulto. Barueri: Manole, 2002. Cap. 2, p.27-45.

BENEVIDES, C. M. Leite de búfala: qualidades tecnológicas. Higiene Alimentar, São Paulo, v.12, n.54, p.18-21, mar. 1998.

BRASIL. Ministério da Agricultura, Pecuária e Abastecimento. Padrão de identidade e qualidade de leites fermentados. Resolução n. 05, de 13 de novembro de 2000. Brasília, 2000.

CORDEIRO, A. M. Avaliação físico-química e sensorial de bebida simbiótica fermentada com Lactobacillus casei e suplementada com Bifidobacterium longum e extrato de cenoura (Daucus carota L.). 1999. Dissertação (Mestrado) - Universidade Federal de Viçosa, Viçosa.

FERREIRA, C. L. L. F. Valor nutricional e bioterapêutico de leites fermentados. Leite \& Derivados, São Paulo, v.6, n.36, p.46-52, 1997.

FERREIRA, C. L. L. F. Produtos lácteos fermentados: aspectos bioquímicos e tecnológicos. Viçosa: Ed. UFV, 2001.112 p.

GOMES, A. M. P.; MALCATA, F. X. Bifidobacterium spp. and Lactobacillus acidophilus: biological, biochemical, technological and therapeutical properties relevant for use as probiotics. Trends in Food Science and Technology, Cambridge, n.10, p.139-157, 1999.
HUHN, S.; LOURENÇO JUNIOR, J. B.; MOURA C. L. O. D.; NASCIMENTO, C. N. B.; VIEIRA, L. C. Aproveitamento do leite de búfala em produtos derivados. In: SIMPÓSIO DO TRÓPICO ÚMIDO,1., 1984, Belém. Anais... Belém: Embrapa-Cpatu, 1986. v.5, p.265-269. (Documentos, 36).

HUHN, S.; LOURENÇO JUNIOR, J.B.; MOURA CARVALHO,L.O.D.; NASCIMENTO, C.N.B.; VIEIRA,L.C. Características, peculiaridades e tecnologia do leite de búfala. Belém: Embrapa-Cpatu, 1991. (Documento 57)

HOLT, J. G.; BERGEY, D.H.; KRIEG, N. R.; SNEATH, P. H.A. Bergey's manual of determinative bacteriology. 9.ed. Baltimore: Willian \& Wilkins, 1994.

KRAUSE, M. M. Alimentos, nutrição e dietoterapia. São Paulo: Roca, 1998. 1179 p.

LEE, Y.; SALMINEN, S. The coming of age of probiotics. Trends in Food Science and Technology, Cambridge, v.6, p. 241-245, 1995.

TAMINE, A. Y.; MARSHALL, V. M. E.; ROBINSON, R. K. Microbiological and technological aspects of milk fermented by Bifidobacteria. Journal of Dairy Research, London, v.62, p.151-187, 1995.

TRABULSI, L. R. Flora intestinal, probióticos, prebióticos e simbióticos. São Paulo: Nestlé, 2000. (Temas de Pediatria Nestlé)

TRABULSI, L.R.; SAMPAIO, M.M.S.C. Probióticos, prebióticos e simbióticos. In: TRABULSI, L.R.; CARNEIRO-SAMPAIO, M.M.S. Os probióticos e a saúde infantil. São Paulo: Nestlé, 2000. p.15 (Temas de Pediatria Nestlé, 3)

VANDERZANT, C.; SPLITTSTOESSER, D. F. Compendium of methods for the microbiological examination of food. Washington: American Public Health Association, 2002.

VINDEROLA, C. G.; REINHEIMER, J. A. Enumeration of Lactobacillus casei in the presence of L. acidophilus, bifidobacteria and lactic starter bacteria in fermented dairy products. International Dairy Journal, Barking, v.10, p.271-275, 2000.

WALSTRA, P. On the stability of casein micelles. Journal of Dairy Science, Champaign, v.73, p.1965-1969, 1990. 
